\title{
Diffuse hypertrophy of the cerebellum
}

\author{
THOMAS COOK, SHIRLEY HOLT, AND P. O. YATES \\ From the Department of Pathology, University of Manchester
}

This condition, which has masqueraded under many names, is probably best termed 'diffuse hypertrophy of the cerebellum', though the more recent papers from the United States (Courville, 1958, 1960; Christian, 1961) apparently favour the term 'gangliocytoma'. Since the initial description of Lhermitte and Duclos (1920) other reports have appeared scattered in the literature. Reviews have been published by Oppenheimer (1955), Courville (1958), and more recently by Hallervorden (1959). The latter described 21 cases but did not include those of Bignami and De Matteis (1956) and of Courville (1958). Further cases have been reported by Courville (1960) and Christian (1961). The total number of cases, including that described below, is thus 26 , of which there have been three survivors.

\section{CLINICAL}

HISTORY The patient (M.R.I. 60/10598), a single woman aged 25, was admitted to the Department of Neurosurgery, Manchester Royal Infirmary, as an emergency on 11 May 1960, complaining of headache, vomiting, and diplopia.

She had for many years been subject to bifrontal headache accompanying recurrent attacks of maxillary sinusitis, which symptoms were considerably but incompletely relieved by a left Caldwell-Luc operation at the age of 20 years. It was, however, the increasing severity of similar headache over the previous month, quickly followed by the onset of vomiting, which led her to seek medical advice. The vomiting, which was not projectile, occurred only in the mornings and was preceded by nausea immediately on waking. In the three weeks before admission she had experienced intermittent diplopia most marked on looking straight ahead. On further questioning she admitted to brief episodes of neck stiffness over the previous two months and slight occipital headache on the day of admission.

Two other interesting and probably significant features were her spontaneous admission that all through her life her left hand had been 'clumsier' than her right without there being any actual ataxia, and the observation of friends that she had been 'generally slowing up' in her duties for three or four months.

There were no other notable events in her previous medical history. The family history was likewise of no significance.
EXAMINATION The patient was a slim, healthy-looking young woman. Examination of the central nervous system showed her to be fully conscious and orientated, with memory and powers of concentration unimpaired. There was slight bilateral hyposmia and bilateral papilloedema. Visual acuity was $\mathrm{J} 1$ in each eye. Ocular movements were full, but there was coarse nystagmus and difficulty in maintaining gaze to the right. Hypoalgesia to pinprick was noted in the territory of the left trigeminal nerve. Examination of the remaining cranial nerves revealed no abnormality. Power and tone in the limbs and trunk were normal, but coordination was impaired and dysdiadochokinesis was seen on the left. The left triceps and ankle jerks were increased and both plantar responses were extensor. Kernig's sign was negative, and there was no nuchal rigidity.

Examination of the abdomen and of the cardiovascular and respiratory systems was normal. Blood pressure was $125 / 80 \mathrm{~mm}$. Hg.

INVESTIGATION A radiograph of the chest was normal.

Radiographs of the skull showed diastasis of the coronal and metopic sutures with a tendency to "copper beating'. The pituitary fossa was normal in size but had a porotic floor. The pineal body was uncalcified.

A Myodil ventriculogram showed that the pressure of cerebrospinal fluid in the ventricle was only slightly raised. There was some dilatation of the whole ventricular system. A 'dog-leg' deformity of the iter with shift of the fourth ventricle to the right was present, suggesting a high space-occupying lesion in the left cerebellar hemisphere.

OPERATION Using assisted respiration a wide left craniectomy was performed in the posterior fossa. 'Tumour' was seen through the dura high in the postero-superolateral quadrant of the left cerebellar hemisphere. This area was firm and abnormally white, showing that the folial pattern was preserved, though the folia were patchily thickened. Pressure was high. The lesion appeared, falsely, to be demarcated from the normal cerebellum at the horizontal fissure. An attempt was made to remove the affected part of the cerebellar hemisphere, but this proved impossible because the 'tumour' spread across the mid-line in the vermis, over the superior surface of the left hemisphere and around the internal auditory meatus where the arachnoid appeared to be involved and was adherent to the auditory and facial nerves. The portion of 'tumour' removed was considerable, being $6 \mathrm{~cm}$. in diameter. The dura was closed completely.

On her return from the theatre the patient's respiratory 
rate was only 12 per minute, but nine hours later this had returned to normal. Throughout the immediate postoperative period she could always be roused without difficulty, and would talk spontaneously. Her further recovery was uneventful, and she was discharged home 11 days after operation.

At the follow-up clinic one month later her only complaint was of two episodes of unsteadiness and vomiting. The residual physical signs were nystagmus, fine to the right, and a little slower to the left, and possibly slight left facial weakness. Left-sided ataxia remained but was less than pre-operatively. Treatment with prochlorperazine was started and after a further month, apart from occasional trivial dizziness, she felt well. The fundi were by this time flat, but with indistinct edges.

Her most recent visit to the clinic was 10 months postoperatively on 6 March 1961. Movements on the left side were still slightly ataxic and movements of the individual fingers of the left hand could not be performed. This, however, represented no deterioration over her preoperative condition. Dizziness now occurred only occasionally on turning her head. Both optic discs were flat but were highly coloured. She had returned to full-time employment in a responsible post. Further follow-up was arranged for 12 months.

\section{PATHOLOGY}

Precise and detailed accounts of the pathology of this lesion are contained in most of the previous descriptions. Since the pathology of this case conforms with these previous accounts, it needs here but a relatively brief description.

Macroscopically, the folia in the operative specimen were confirmed to be unduly white and to be extensively, but nevertheless patchily thickened to two or three times normal (Fig. 1). Histologically the central white matter has become markedly

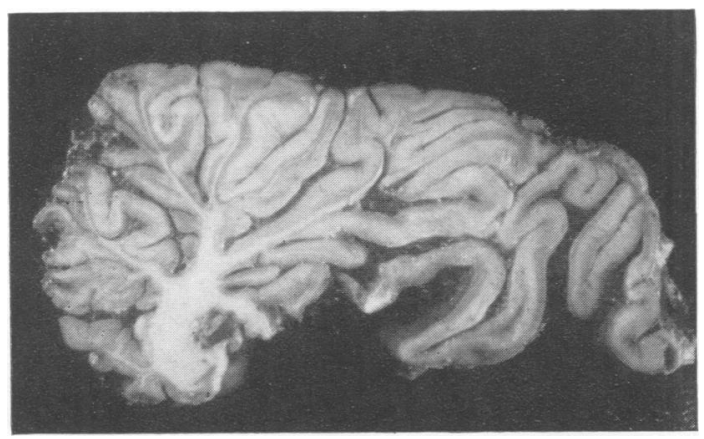

FIG. 1. Naked-eye view of part of the operative specimen showing the patchy broadening of the folia, a good example of which is to be seen in the upper left-hand part of the figure. The folia, which are seen in cross-section, demonstrate marked thickening and undue pallor of the molecular layer, and near disappearance of the central white matter. thinned or has disappeared altogether. In contrast, the molecular layer, composed of large fibres running parallel to the folia, is thickened to $0.8-0.9 \mathrm{~mm}$. Many of these fibres are myelinated. Among these fibres are a few small glial nuclei, about $12 \mu$ in diameter, and very occasional neurones identical to those in the altered granular layer. The part of the cortex conforming with the granular layer is also thickened $(0.75 \mathrm{~mm}$.) being composed of large ganglion cells of similar size to Betz or Purkinje cells, the axons of which are seen in the granular layer (Fig. 2).

At the periphery of the lesion (Fig. 3) granule neurones are gradually replaced by these ganglion cells; forms intermediate between the two can be identified. Calcification of small vessels in the leptomeninges as described by Oppenheimer (1955) and Courville (1960) was not seen in this case.

\section{DISCUSSION}

From a study of the previous literature, this condition appears to present two outstanding problems. What is the origin of the abnormal cells? And is the lesion truly neoplastic? Earlier authors supported the view that the abnormal cells are derived from the granular layer, though Foerster and Gagel (1933) and later Christensen (1937) and still more recently Courville (1958) have favoured an origin in the Purkinje neurones, Christensen indeed coining the name 'Purkinjeoma'. Several features of the lesion, however, reinforce the suggestion of a granule cell origin: there is the position of the cells in the granular layer, and the fact that, like the granule neurones, the fibres of these abnormal cells run parallel to the folia. Furthermore, intermediate forms between the abnormal cells and granule neurones, but not Purkinje neurones, can be seen at the margins of the abnormal tissue. Purkinje cells either appear degenerate or have disappeared altogether; nor is anything resembling Purkinje dendrites to be seen. It is well known that Purkinje neurones are sensitive to adverse conditions. Such conditions could in this case have resulted from pressure by the mass of the lesion, diversion of metabolites to the abnormal cells, or diminution of blood supply. Possibly, even, the degenerative changes could be the result of an altered physiology in the metamorphosed granule neurones, with whose axons the Purkinje dendrites synapse. The thinning or disappearance of the central white matter is possibly the result of pressure or ischaemia; it could hardly be accounted for by the disappearance of Purkinje axons.

With regard to the nature of the lesion, Lhermitte and Duclos in the original paper came to no definite conclusion as to whether this was a true neoplasm or a congenital malformation. Ten years later Biel- 


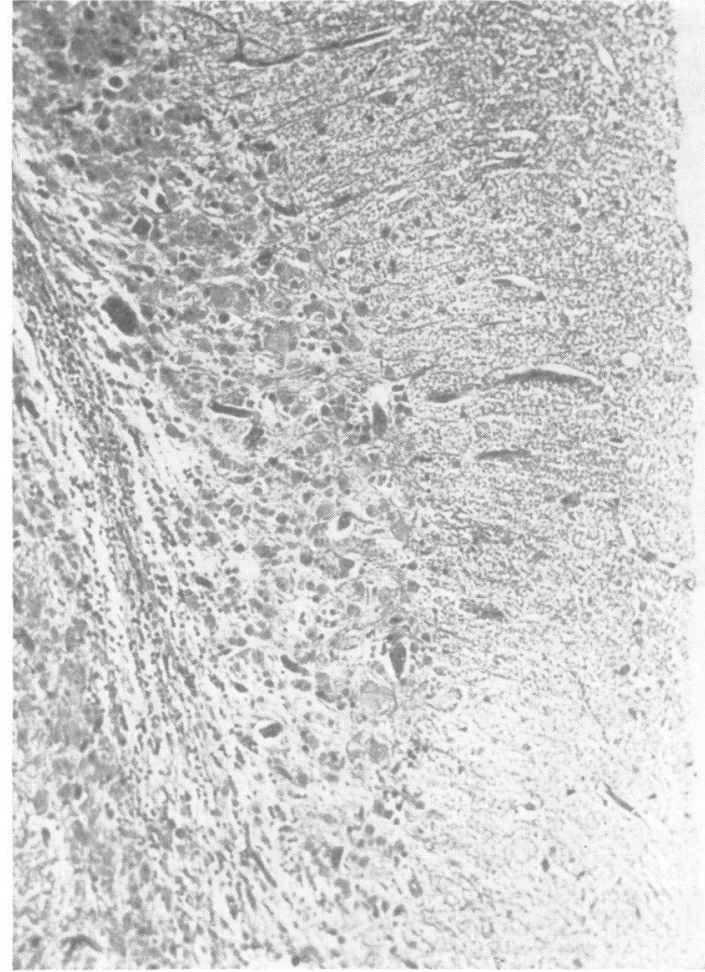

FIG. 2

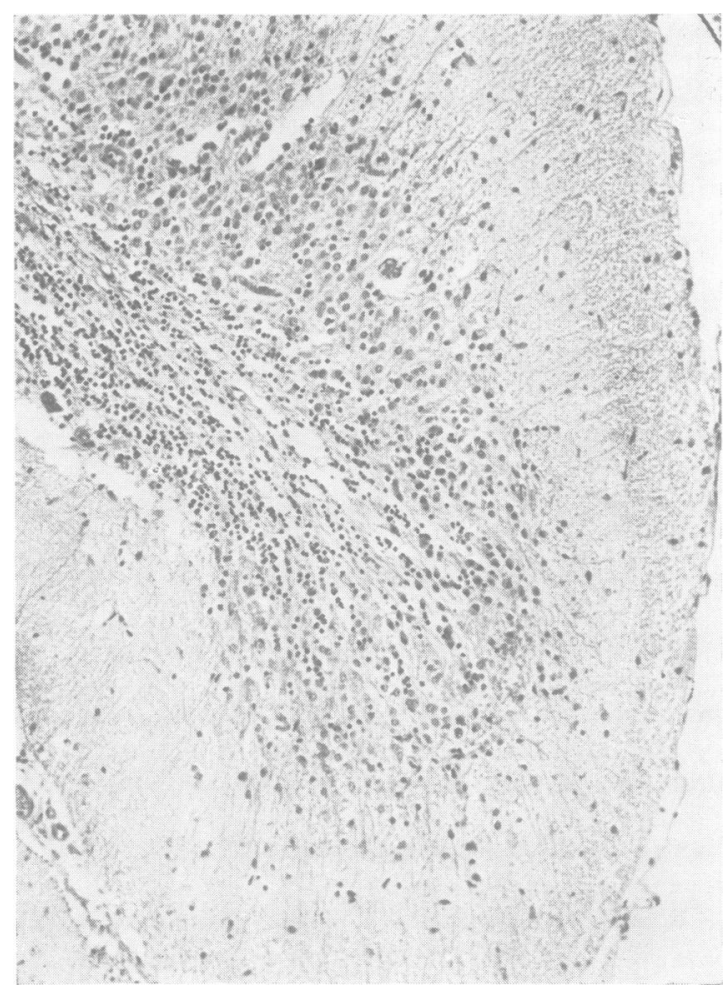

FIG. 3

FIG. 2. The affected cerebellar folia show replacement of the granule neurones by large ganglion cells. The molecular layer is hypertrophied and the central white matter is thinned. Haematoxylin and eosin $\times 140$.

FIG. 3. At the periphery of the lesion there is gradual replacement of the granule neurones by 'ganglion cells'.

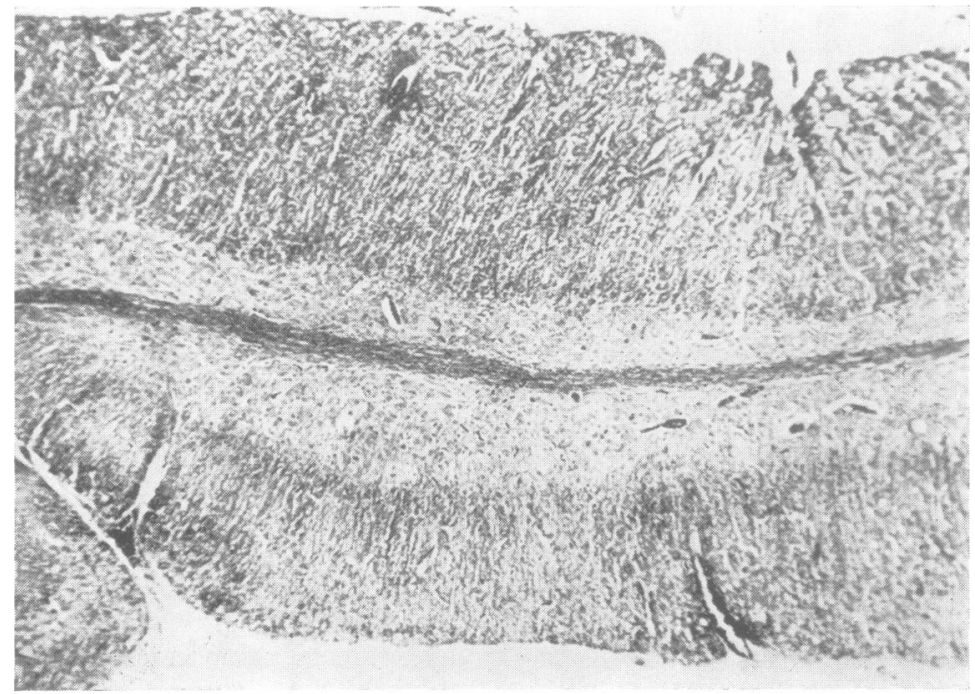

FIG. 4. The molecular layer of the affected folia is thickened and abnormally hypermyelinated. The central white matter is by contrast markedly thinned. Weil $\times 35$. 
schowsky and Simons (1930) also were not prepared to offer a firm opinion but re-emphasized the possibility that this was a congenital malformation. A novel view was introduced by Duncan and Snodgrass (1943) with their 'hypertrophic' theory, which suggested that this lesion was produced by an increase in size of the normal cells of the granular layer so that they were no longer recognizable as such: the hypertrophy of the molecular layer was the result of thickening and myelination of the associated nerve fibres.

There is good evidence in favour of this lesion not being neoplastic. The layers are arranged in an orderly pattern conforming with those seen in the normal cerebellum, and the large abnormal cells appear quiescent, with a notable absence of mitoses, showing but little tendency to infiltrate the molecular layer. The association of other congenital abnormalities in several of the cases (Bielschowsky and Simons 1930; Barten, 1934; Carbone, Brihaye, and Drochmans, 1955) must also favour this being a developmental anomaly.

It would seem, therefore, desirable to term the abnormal cells 'ganglion cells' rather than follow the trend of Bielschowsky and Simons (1930) and later authors in calling them 'neuroblasts', with its inherent implication of neoplasia, particularly in view of their large, well-developed axons. The thickening of these fibres is most easily explained as an accompaniment to the increase in cell size though this still leaves unexplained the hypermyelination (Fig. 4).

The 'hypertrophic theory' of Duncan and Snodgrass is attractive in so far as an increase in cell and fibre size, without implying either an increase in cell numbers or the replacement of functioning neurones by tumour cells, would cause the lesion to present predominantly, though not exclusively, with symptoms of pressure. If, then, it is to be suggested that this is an inherent defect of, rather than a neoplastic change in, granule neurones, an explanation must be suggested for the onset of symptoms in adult life rather than in childhood. Several authors have commented on the presence of intermediate forms between granule neurones and ganglion cells. A con- tinuous progression of normal to abnormal cells could be taking place: the patchiness of the lesion suggested that all the granule neurones might have this potential. Symptoms would then occur when the bulk of the lesion results in obstruction to the flow of cerebrospinal fluid or interference with the transmission of impulses.

\section{SUMMARY}

This study describes a further case of diffuse hypertrophy of the cerebellum in a 25 -year-old woman. There was a doubtful history of slight unilateral ataxia over 20 years or more, with eventually an episode of raised intracranial pressure. The lesion, in the postero-supero-lateral quadrant of the left cerebellar hemisphere, was incompletely removed at operation. Biopsy showed metamorphosis of the granular layer into larger ganglion cells, with thickening and hypermyelination of the molecular layer, and narrowing of the central white matter. The patient recovered with little or no disability, and returned to full-time employment in a responsible post.

We thank Professor A. C. P. Campbell for his assistance in the preparation of this paper, and Mr. R. T. Johnson for permission to use the clinical details of his case.

\section{REFERENCES}

Barten, H. (1934). Beitr. path. Anat., 93, 219.

Bielschowsky, M., and Simons, A. (1930). J. Psychol. neurol. (Lpz.), 41, 50.

Bignami, A., and De Matteis, A. (1956). Riv. Anat. pat., 11, 523.

Carbone, F., Brihaye, J., and Drochmans, P. (1955). Acta neurol. belg., 55, 568.

Christian, H. J. (1961). J. Neurosurg., 18, 125.

Christensen, E. (1937). Virchows Arch. path. Anat., 300, 567.

Courville, C. B. (1958). Bull. Los Angeles Neurol. Soc., 23, 72.

(1960). Ibid., 25, 232.

Duncan, D., and Snodgrass, S. R. (1943). Arch. Neurol. Psychiat. (Chicago)., 50, 677.

Foerster, O., and Gagel, O. (1933). Z. ges. Neurol. Psychiat., 146, 792. Hallervorden, J. (1959). Dtsch. Z. Nervenheilk., 179, 531.

Lhermitte, J., and Duclos, D. (1920). Bull. assoc. franc. Etude Canc., 9, 99.

Oppenheimer, D. R. (1955). J. Neurol. Neurosurg. Psychiat., 18, 199. 